\title{
A Study of Knowledge and Practical Skill Performance in University Students: A Comparison of Technology Enriched versus Traditional Classroom Instruction
}

\author{
Adrian W. Eads \\ Weber State University, adrianeads@mail.weber.edu \\ J. Jordan Hamson-Utley \\ Weber State University
}

Follow this and additional works at: https://nsuworks.nova.edu/ijahsp

Part of the Medicine and Health Sciences Commons

\section{Recommended Citation}

Eads AW, Hamson-Utley J. A Study of Knowledge and Practical Skill Performance in University Students: A Comparison of Technology Enriched versus Traditional Classroom Instruction. The Internet Journal of Allied Health Sciences and Practice. 2014 Apr 01;12(2), Article 10.

This Manuscript is brought to you for free and open access by the College of Health Care Sciences at NSUWorks. It has been accepted for inclusion in Internet Journal of Allied Health Sciences and Practice by an authorized editor of NSUWorks. For more information, please contact nsuworks@nova.edu. 


\title{
A Study of Knowledge and Practical Skill Performance in University Students: A Comparison of Technology Enriched versus Traditional Classroom Instruction
}

\begin{abstract}
Context: Technology is increasingly utilized in the delivery of athletic training education. Hand-held technology affords continued education outside the classroom. Purpose: To determine the effect of mobile technology on the acquisition of knowledge and practical skills in a university upper extremity evaluation course. Design and Setting: A cohort retrospective archival assessment in a university office environment of grades and performance on written and practical examinations in an upper extremity evaluation course. Participants: Sixty-four college age participants (male $n=35,54.69 \%$, female $n=29,45.31 \%$ ) previously enrolled in an undergraduate or graduate athletic training program who completed the upper extremity evaluation course between Spring 2009 and Spring 2012. Main Outcome Measures: Dependent variables included final written examination score, final oral practical examination score, and final grade. The independent variable was the technology-enriched instruction provided using the Flashcards Deluxe application available on Android, Apple iPod Touch, iPhone, or iPad devices. This application allows participants to study electronic flashcards with text, pictures, and sound on a mobile device. The control group did not receive the technology-enriched instruction. Results: A one-way between subjects ANOVA was conducted to compare the effect of technology on final written examination, final oral practical examination, and overall grade. There was a significant effect on the final written examination $[F(1,63)=$ 11.621, $\left.p=.001, \eta^{2}=.158\right]$; however, oral practical examination $\left[F(1,63)=0.348, p=.557, \eta^{2}=.006\right]$ and overall grade $\left[F(1,63)=0.695, p=.408, \eta^{2}=.011\right]$ were not significant. Conclusion: Participants with technologyenriched instruction performed significantly better on their final written examination. Based on the findings, technology-enriched instruction improves a student's knowledge comprehension of orthopedic principles of evaluation. Student performance was improved on written examinations following the use of electronic flashcards. Based on the findings in this study, technology-enriched instruction improves a student's comprehension of upper extremity evaluation knowledge. It is reasonable to believe the use of flashcards would assist in student comprehension in other learning areas as well.
\end{abstract}

\section{Author Bio(s)}

- Adrian W. Eads, MS, LAT, ATC, Athletic Trainer, Weber State University, Ogden, Utah.

- J. Jordan Hamson-Utley, PhD, LAT, ATC, Assistant Professor of Athletic Training, Weber State University, Ogden, Utah. 


\title{
TIAHSP \\ The Internet Joutnal of Allied Health Sciences and Practice \\ Dedicated to allied health professional practice and education \\ http://ijahsp.nova.edu Vol. 12 No. 2 ISSN 1540-580X
}

\section{A Study of Knowledge and Practical Skill Performance in University Students: A Comparison of Technology Enriched versus Traditional Classroom Instruction}

\author{
Adrian W. Eads, MS, LAT, ATC. 1 \\ J. Jordan Hamson-Utley, PhD, LAT, ATC.2,3
}

1. Athletic Trainer, Weber State University, Ogden, Utah

2. Assistant Professor of Athletic Training, Weber State University, Ogden, Utah

3. University of Phoenix, SAS

United States

\begin{abstract}
Context: Technology is increasingly utilized in the delivery of athletic training education. Hand-held technology affords continued education outside the classroom. Purpose: To determine the effect of mobile technology on the acquisition of knowledge and practical skills in a university upper extremity evaluation course. Design and Setting: A cohort retrospective archival assessment in a university office environment of grades and performance on written and practical examinations in an upper extremity evaluation course. Participants: Sixty-four college age participants (male $n=35,54.69 \%$, female $n=29,45.31 \%$ ) previously enrolled in an undergraduate or graduate athletic training program who completed the upper extremity evaluation course between Spring 2009 and Spring 2012. Main Outcome Measures: Dependent variables included final written examination score, final oral practical examination score, and final grade. The independent variable was the technology-enriched instruction provided using the Flashcards Deluxe application available on Android, Apple iPod Touch, iPhone, or iPad devices. This application allows participants to study electronic flashcards with text, pictures, and sound on a mobile device. The control group did not receive the technology-enriched instruction. Results: A one-way between subjects ANOVA was conducted to compare the effect of technology on final written examination, final oral practical examination, and overall grade. There was a significant effect on the final written examination $\left[F(1,63)=11.621, p=.001, \eta^{2}=.158\right]$; however, oral practical examination $\left[F(1,63)=0.348, p=.557, \eta^{2}=.006\right]$ and overall grade $\left[F(1,63)=0.695, p=.408, \eta^{2}=.011\right]$ were not significant. Conclusion: Participants with technology-enriched instruction performed significantly better on their final written examination. Based on the findings, technology-enriched instruction improves a student's knowledge comprehension of orthopedic principles of evaluation. Student performance was improved on written examinations following the use of electronic flashcards. Based on the findings in this study, technology-enriched instruction improves a student's comprehension of upper extremity evaluation knowledge. It is reasonable to believe the use of flashcards would assist in student comprehension in other learning areas as well.
\end{abstract}

\section{INTRODUCTION}

Athletic training is expected to grow much faster as compared to other allied health care occupations between now and 2020.1 As a result, there will be an increase in the demand for educational institutions to develop students into competent athletic trainers, ready to enter the workforce. Over 70 percent of athletic trainers hold at least a master's degree. ${ }^{2}$ Many students seek advanced degrees to continue competing in the workforce and may seek additional education after entering the workforce. As a result, many students are older than 18 to 22 and considered "non-traditional." Athletic training education programs are faced with technology-enriched pedagogical demands with the combination of growth in the field and a changing student population. ${ }^{3}$ Students have a variety of learning options including hybrid courses, online degrees, and traditional face-to-face instruction with the advance of technology over the past 10 years. Mobile classrooms, through the use of technology, meet the demands of the non-traditional, multi-tasking students who are likely to have additional responsibilities and demands while they attempt to complete their education. The mobile classroom enables multi-tasking students to fit education into their lives via mobile flashcards that can be viewed on the train/bus, by listening to lectures while waiting for an appointment, or by viewing 
coursework while on a break at work or while watching their kids at the playground. ${ }^{4}$ Enabling mobile access educational content maximizes learning opportunities and empowers the student to learn in ways that work for them, thereby improving their overall educational experience. ${ }^{5}$ Most students have multiple technology devices which are used for both personal and educational activities. ${ }^{4,} 5$ Houston Community College piloted a study that found students who utilized iPod technology spent more time studying, interacting with their classmates, and watching course videos than the control group who did not utilize mobile technology. Additionally, students with iPods also felt that learning was more flexible as they could log into their course at any time and at any place. 6,7

Specific to the athletic training program (ATP), various researchers have found that technology fits with both synchronous and asynchronous pedagogies. $3,8-10$ Students in the ATPs are assigned to various clinics where they may not be able to use course materials, such as notes and textbooks. Mobile learning devices allow classroom education to continue in the clinical setting and may even benefit the preceptor as well; when a question arises that the preceptor cannot answer, the student and the preceptor can reference course materials or the Internet right then using the device. Researchers have also found learning is more flexible and students are able to document their clinical experiences more effectively with mobile devices. ${ }^{1}$ Finally, exploring satisfaction, students in the ATP like it and consider it a time-efficient method of learning. ${ }^{3,8-10}$

Mobile devices offer learning flexibility, afford opportunity to create program-based content libraries, and provide ease in information transmittal. Additionally, both instructors and students have 24/7 access to textbooks, digital flashcards, and podcasts. ${ }^{11}$ Educators and students can generate innovative content not previously available in traditional classrooms through the use of these digital resources supporting prosumer content (student generated and student consumed) that is considered a creative, modern pedagogy. ${ }^{12}$ Technology has created a new culture of learning, allowing learning to be a shared project between students and their teachers. ${ }^{13}, 14$ Within the next decade, a significant number of course activities will be delivered using mobile devices and many courses will transition to a hybrid model where lectures are available pre-recorded and classroom time is spent applying lecture content. ${ }^{15}$

The purpose of this research was to examine the effects of technology-enriched instruction on athletic training student written and oral practical skill comprehension compared to traditional classroom instruction. The research was guided by the following question: Does the use of mobile learning in the way of digital flashcards effect student performance on written examinations, practical skill examinations, and/or overall final course grades?

\section{METHODS}

A cohort retrospective archival comparison of final grades and performance on unit written and oral practical examinations for an orthopedic upper extremity evaluation course over five semesters with a mobile learning technology intervention (Flashcards Deluxe App https:/itunes.apple.com/us/app/flashcards-deluxe/id307840670?mt=8). Two semesters without mobile learning (control group) were followed by three semesters that included the implementation of the Flashcards Deluxe App on iPods. The same professor, who is considered an expert in orthopedic evaluation, taught all classes included in this study. All participants used the same textbook; course content remained unchanged across semesters (1.5 academic years).

Written and oral practical exams were given at the end of each unit ranging from two to three weeks for both the control and intervention groups; final grades were calculated by averaging all written and oral practical exam scores and were calculated by percentage scores. For the purposes of this study, a letter grade was not utilized, thus a grading scale matching percentages and letter grades was not provided.

In the intervention group, participants either used their own handheld device or were issued an Apple iPod Touch (Apple Inc., Cupertino, CA) at the beginning of the semester. Participants were instructed in-class (25 minutes) on how to utilize the Flashcards Deluxe App and given flashcard deck codes for download at the beginning of each new unit (five units included shoulder, elbow, wrist/hand, head/neck, and thorax/abdomen). The course instructor to control for accuracy, visual appeal, and content clarity created the flashcard decks; decks were not modified throughout the course of this study. Online resources were provided to support students in case of questions on App features/use www.orangeorapple.com and http://www.youtube.com/watch?v=AGNgBmZt2lg).

A sample deck used in this study can be found here: https://dl.dropbox.com/u/29674903/Shoulder\%20Flashcards.xlsx.

(C) The Internet Journal of Allied Health Sciences and Practice, 2014 


\section{PARTICIPANTS:}

After securing IRB approval, a list of potential participants was generated from those students who took Upper Extremity Evaluation as the only inclusion criteria. Additionally, students who were enrolled in Upper Extremity Evaluation for three semesters were approached to participate in the study. All participants were contacted, delivered the informed consent, and permission was obtained to access their grades from the upper extremity evaluation course. A total of 64 participants (male $n=35,54.69 \%$, female $n=29,45.31 \%$ ) agreed to take part in the study. Five semesters of the course were taught with three semesters receiving the technology intervention $(n=50,78.1 \%)$ and the other two semesters being taught traditionally $(n=14$, $21.9 \%$ ). Courses without technology were instructed first, controlling for the potential threat of technology sharing across sections.

\section{ANALYSIS}

Data were entered in SPSS 20 (SPSS Inc., Chicago, IL) for analysis. A one-way ANOVA was used to analyze for an effect of technology-enriched instruction by looking for between group differences.

\section{RESULTS}

A one-way between subjects ANOVA was conducted to compare the effect of technology on final written examination, final oral practical examination, and overall grade. There was a significant effect on the final written examination $[F(1,63)=11.621, p=.001$, $\left.\eta^{2}=.158\right]$; however, oral practical examination $\left[F_{(1,63)}=0.348, p=.557, \eta^{2}=.006\right]$ and overall final grade $\left[F_{(1,63)}=0.695, p=.408\right.$, $\left.\eta^{2}=.011\right]$ were not significant.

\section{DISCUSSION}

Athletic trainers, like many other health professions, rely on both knowledge and practical skills to interact with patient populations. In addition to focusing on their education, these students also must balance outside employment and family responsibilities. They can obtain an education while managing other demands by having the ability to multi-task and study on their terms through the use of a mobile classroom, ${ }^{4}$ Additionally, it has been shown that self-studying is more efficient in knowledge acquisition than traditional lectures. ${ }^{16}$ One way students can self-study using handheld technology is through the use of electronic flashcards.

Our study examined the effects of technology-enriched instruction on final written examination, final oral practical examination, and final grade. We found significant findings on the effect of electronic flashcards on the final written examination. Electronic flashcards result in information being easily accessible to learners. Research has shown learning cannot occur unless the student understands what is being reinforced. ${ }^{17}$ In our study, the participants recognized the reinforced information contained in the electronic flashcards, which resulted in improved performance on the final written examination. Additionally, repetition is a powerful learning tool. ${ }^{18}$ The use of electronic flashcards provides repetition to important information to the student and leads to better recollection while taking the written examination. Using electronic flashcards the participants had access to study material 24/7 regardless of where their textbook was. This method of e-learning appears to be supported in an evaluation course in athletic training education much as it was in the study conducted by Wright et al. ${ }^{3}$ Student performance on written examinations is important for athletic training education, as the national certification examination is $100 \%$ written.

Our study also evaluated the use of electronic flashcards on oral practical examination scores. There was not a statistically significant effect on oral practical examination scores (no technology $=92.21 \pm 6.71$, technology $M=90.28 \pm 11.69$ ). In reviewing the data, it appears the participants performed slightly worse with the use of technology. Statistically they performed similarly. This may be attributed to the oral practical examination required the participants to perform special tests with their hands properly placed on anatomical landmarks. The electronic flashcard program used in this study does not allow the use of videos so participants cannot rely on flashcards to perform well on this type of examination.

Finally, our study evaluated the use of electronic flashcards on overall final grade. There was not a statistically significant effect on the final grade (no technology $=91.47 \pm 6.55$, technology $=92.60 \pm 3.77$ ). This is likely due to the other course assignments such as participation and writing assignments, which are not related to flashcard use.

We recognize the small and unbalanced nature of our sample size in this study; with only 14 subjects in our control group compared to the 50 subjects in the intervention. However, the Levene's test is not significant $F_{(1,63)}=0.210, p=0.648$ at the .05 alpha level. Thus, the assumption of homogeneity of variance is met (i.e. not violated) for this sample. While the groups were unbalanced, they were statistically stable. When the instructor began teaching the course, the Flashcard Deluxe application was not available. After it became available, it also coincided with more students being accepted into the athletic training program. As electronic flashcards have now been available in this course for several years, it is not possible to gain additional subjects when

(c) The Internet Journal of Allied Health Sciences and Practice, 2014 
the flashcards are known in the course and expected by the students. Additionally, as electronic flashcards have been shown to have a significant effect on the final written examination it would be unfair to penalize future students by not offering them this study aid. The sample size of our study is similar to other studies conducted on mobile learning using electronic devices, as few peer-reviewed studies have been conducted utilizing electronic flashcards in education with the largest published study having 80 subjects. ${ }^{19}$

This research has broad impacts for allied health profession education. Many allied health professions require national examinations, which typically involve a written component, to obtain certification. Our study has shown student performance was improved on written examinations following the use of electronic flashcards. With changing and unpredictable workloads, healthcare workers have the opportunity to self-educate by having access to material anywhere and anytime. ${ }^{20}$ Therefore, it is reasonable to believe if allied health education programs employed technology-enriched instruction, students may perform better in both course written examinations and on the written portion of the national examination.

Future research should evaluate the use of electronic flashcards with a balanced group of participants and over several athletic training subjects. Research should also evaluate if electronic flashcards have the same effect and are utilized by a traditional student population. If videos are available on electronic flashcards, this may have an effect on other aspects of student performance such as oral practical examinations and overall final grade. Finally, future researchers should evaluate the impact of having students create their own electronic flashcards.

\section{CONCLUSIONS}

These findings are important; as it shows technology-enriched instruction is beneficial for students in preparing for written examinations. Based on the findings in this study, technology-enriched instruction improves a student's comprehension of upper extremity evaluation knowledge. It is reasonable to believe the use of flashcards would assist in student comprehension in other learning areas as well. Regarding practical skills, if Flashcards Deluxe could utilize videos of special tests, the use of technology may have an impact on practical skills and the overall final grade. Further work is needed to determine the effect of technology in a learning environment on different age groups and gender.

Funding for this research was received through the Dee Family Technology Grant, Ogden, Utah (Adrian Eads) in the amount of $\$ 4,300$ (Grant \# D12-07). The authors do not have any commercial or proprietary interest in the technology applications or devices used in this study.

\section{REFERENCES}

1. Bureau of Labor Statistics. Athletic Trainers: Occupational Outlook Handbook: U.S. Bureau of Labor Statistics. 2012. Available at: http://www.bls.gov/ooh/healthcare/athletic-trainers.htm. Accessed August 14, 2012.

2. National Athletic Trainers' Association. Athletic Training. 2012. Available at: http://www.nata.org/athletic-training. Accessed February 18, 2014.

3. Wright KE, Stewart J, Wright VH, Barker S. Elearning: Is there a place in athletic training education? J Athl Train. 2002; 37(4 Suppl):S208-12. [PMID 12937546].

4. Dahlstrom E, de Boor T, Grunwald P, Vockley M. ECAR study of undergraduate students and information technology 2011. Boulder, CO: EDUCAUSE Center for Applied Research; 2011. Available at: http://www.educause.edu/ecar . Accessed January 15, 2012.

5. Dahlstrom E. ECAR study of undergraduate students and information technology 2012. Louisville, CO: EDUCAUSE Center for Applied Research; 2012. Available at: http://www.educause.edu/ecar. Accessed November 12, 2012.

6. Young JR. A teaching-tool face-off: iphones vs. pc's. Chron High Educ. 2009;55(27):a13.

7. Saltalamachia JD. Podcasts, powerpoint, and pedagogy: using technology to teach the part-time student. NY Law Sch Law Rev. 2008;53(3/4):893-900.

8. Fincher AL, Wright KE. Use of computer-based instruction in athletic training education. J Athl Train. 1996;31(1):44. [PMID 16558370].

9. Pitney WA, Parker J. Qualitative research applications in athletic training. J Athl Train. 2002;37(4 Suppl):s168-73. [PMID 12937540].

10. Wiksten DL, Spanjer J, LaMaster K. Effective use of multimedia technology in athletic training education. J Athl Train. 2002;37(4 Suppl);s213-9. [PMID 12937547].

11. Todaro JB. The ipod.. no shiny metal object here. Comm \& Jun Coll Lib. 200513(4):107-11.

12. Dale C, Pymm JM. Podagogy: The ipod as a learning technology. Act Learn in High Ed. 2009;10(1):84-96.

(C) The Internet Journal of Allied Health Sciences and Practice, 2014 
13. Kukulsa-Hulme A. Learning cultures on the move: where are we heading? J Educ Techno Soc. 2010;13(4):4-14.

14. Schaffhauser D. Education Leaders See MOOCs, Distance Learning as the Future of Higher Ed - Campus Technology. Campus Technology. Available at: http://campustechnology.com/Articles/2012/08/20/Education-Leaders-See-MOOCsDistance-Learning-as-the-Future.aspx?p=1 . Accessed February 18, 2014.

15. Anderson JQ, Boyles JL, Rainie L. Bricks and Clicks: What is the potential future of higher education and the Internet by 2020? Washington, D.C.: Elon University \& Pew Research Center's Internet and American Life Project; 2012.

16. Gijselaers W, Schmidt $\mathrm{H}$. Effects of quantity of instruction on time spent on learning and achievement. Educ Res Eval. 1995;1:183-201.

17. Bandura A. Social learning theory. Englewood Cliffs, N.J.: Prentice Hall. 1977

18. Saville K. Strategies for using repetition as a powerful teaching tool. Mus Educ J. September 2011;98(1):69-75.

19. Schmidmaier R, Ebersbach R, Schiller M, Hege I, Holzer M, Fischer M. Using electronic flashcards to promote learning in medical students: Retesting versus restudying. Med Ed. 2011;45(11):1101-10. [PMID 21988625].

20. Bryce $E$, Choi P, Landstrom M, LoChang J. Using online delivery for workplace training in healthcare. J of Dist Ed. 2008;22(3):149-56. 